\title{
ESTUDO DO CICLO DIÁRIO DA VELOCIDADE DO VENTO EM ÁREA DE TRANSIÇÃO COSTEIRA
}

\author{
Edson R. Marciotto ${ }^{1}$, Paulo G. Iriard ${ }^{2}$, Adaiana F. G. Silva², Gilberto F. Fisch ${ }^{3}$ \\ ${ }^{1}$ Universidade Federal de Santa Catarina, Florianópolis \\ ${ }^{2}$ Instituto Tecnológico de Aeronáutica, São José dos Campos \\ ${ }^{3}$ Instituto de Aeronáutica e Espaço, São José dos Campos
}

\begin{abstract}
Wind data at different levels were collected in a coast area from a 70-m height tower located $200 \mathrm{~m}$ downstream of the shore. Additionally, a sodar placed about $7 \mathrm{~km}$ downstream of the shore were deployed to determine the wind speed profile up to 200. It is observed that nearby the shore the wind time evolution does not present a well characterized diurnal cycle. On the other hand, at $7 \mathrm{~km}$ onshore the diurnal not only is well defined at all levels, but also presents an inversion of the amplitude signal, indicating that momentum transport is acting a effective way.
\end{abstract}

\section{RESUMO}

Dados de vento em diferentes níveis foram coletados em área costeira a partir de uma torre anemométrica de $70 \mathrm{~m}$ a $200 \mathrm{~m}$ do oceano e a partir de um sodar $7 \mathrm{~km}$ distante do oceano. Próximo ao oceano, é observado que a evolução temporal do vento não apresenta um ciclo diário característico. A $7 \mathrm{~km}$ adentro do continente, o ciclo diário não só é bem definido em todos os níveis observados como também apresenta uma inversão de sinal da amplitude, indicando que o transporte de momento age de forma efetiva.

\section{INTRODUÇÃO}

Assim como a temperatura e a umidade, o vento próximo à superfície apresenta variações com escala de tempo de um dia, devido ao aquecimento da superfície. Quando a superfície se aquece, células convectivas sobem e descem transportando momento dos níveis mais altos para os mais baixos. À noite, o transporte vertical é pouco intenso ou inexistente de modo que o vento em níveis mais altos não perde momento para os níveis mais baixos e finalmente 
para a superfície. Esse processo é um dos fatores que dá origem aos jatos de baixos níveis. Observações realizadas na região do Centro de Lançamento de Alcântara $\left(2^{\circ} 19^{\prime} 03\right.$ ” N, 44²2’06” W) durante o período de 01 de abril a 30 de junho em diferentes níveis foram analisadas. Os dados apresentados são médias horárias calculadas a partir de dados de um sodar ( $\sim 7 \mathrm{~km}$ adentro do continente) e de uma torre anemométrica ( $200 \mathrm{~m}$ do oceano) com alcances verticais de $150 \mathrm{~m}$ e $70 \mathrm{~m}$ respectivamente.

\section{RESULTADOS E DISCUSSÃO}

A Fig. 1 (direita) mostra o ciclo diário médio observado pelo sodar para algumas alturas selecionadas. O comportamento geral da evolução temporal do vento é consistente com o que é observado em áreas continentais. Os dados mostram uma inversão da amplitude na evolução temporal, indicando a interação do vento com termas ascendentes. Na Fig. 1 (esquerda), é mostrado como a magnitude do vento medida pela torre anemométrica varia em fase em diferentes alturas. Dessa forma, com o auxílio dos dados da torre anemométrica e tendo em vista que os dados do sodar foram coletados a cerca de $7 \mathrm{~km}$ continente adentro, pode-se inferir que a inversão da amplitude do vento com a altura é devido ao transporte de momento pela convecção livre dentro do continente.
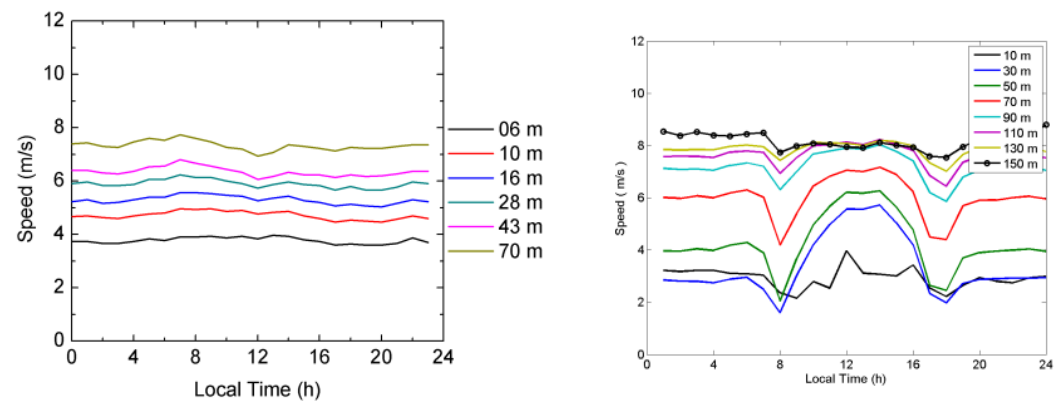

Fig. 1. Ciclo diário do vento observado a $200 \mathrm{~m}$ (esquerda) e a 7 km (direita) do oceano.

De um modo geral, o mecanismo o qual gera o padrão observado na Fig. 1 é bem compreendido qualitativamente. À medida que a superfície se aquece a partir da manhã, termas sobem e descem transferindo momento dos níveis com maior velocidade para os níveis com menor velocidade. A intensificação do vento de superfície durante a manhã é, então, "erosão" da camada de inversão acima. A amplitude da onda do ciclo diário decresce com a altura e fi- 
nalmente fica defasado $180^{\circ}$. A fina camada na qual essa transição ocorre define a região onde o transporte de momento é praticamente nulo. A amplitude atinge um máximo na superfície próximo ao meio-dia. Como dito anteriormente, esse é um padrão típico de áreas continentais e não foi observado na área offshore próxima ao CLA, na qual é observada uma variação em fase entre os níveis.

A próxima etapa deste trabalho é verificar se o modelo WRF é capaz de reproduzir quantitativamente esses padrões. Isso possibilitaria um estudo mais detalhado dos processos de interação atmosfera-superfície e ajudaria a validar as parametrizações de superfície do modelo. Este tipo de estudo é importante também para o planejamento de fornecimento de energia elétrica por meio de turbinas eólicas, uma vez que o dimensionamento do sistema deve levar em conta o vento mínimo.

\section{AGRADECIMENTOS}

Os autores agradecem à FAPESP (processo 2010/16510-0) e ao CNPq (processo 471143/2011-1) pelo suporte financeiro.

\section{REFERÊNCIAS}

Arya S.P., 1988: Introduction to Micrometeorology, Academic Press, San Diego.

Marciotto E.R., Fisch G., 2013: Investigation of approaching ocean flow and its interaction with land internal boundary layer. American Journal of Environmental Engineering, 3, 1823. DOI:10.5923/j.ajee.20130301.04. 